\title{
O BAIRRO E O PLANO DE CONJUNTO PELO URBANISTA LUIZ ARTHUR UBATUBA DE FARIA
}

Adriana Eckert Miranda

Programa de Pós-Graduação em Planejamento Urbano e Regional - PROPUR Universidade Federal do Rio Grande do Sul - UFRGS

Prof ${ }^{a}$ Depto. de Design e Expressão Gráfica -UFRGS

\section{Resumo}

A trajetória profissional do Engenheiro Luiz Arthur Ubatuba de Faria (19081954) possui uma abordagem ampla, se mesclando com a história do urbanismo de Porto Alegre e com o estudo e pesquisa da cidade como campo do saber. No presente artigo, trataremos sobre as idéias desse urbanista em seus primeiros planos, elaborados na década de 30, período de intenso crescimento de Porto Alegre. Estes trabalhos corresponderam a dois níveis de plano: o primeiro, um plano de extensão para um bairro industrial e operário; o segundo, um plano de conjunto para a cidade intitulado Contribuição ao estudo da urbanização de Porto Alegre de 1938 em coautoria com seu colega Edvaldo Pereira Paiva.

Palavras-chave: história do urbanismo; planos; urbanistas.

\section{Abstract}

The professional trajectory of the Engineer Luiz Arthur Ubatuba de Faria (1908 - 1954) has a broad approach, blending itself into the history of Porto Alegre's town planning and the study and research of the city as a field of knowledge. In the present article, we shall discuss about the ideas of this town planner in his first designs, developed in the 30s, time of intense growth to Porto Alegre. These projects corresponded to two levels of planning: the first, a plan for expanding the city for a working class industrial village; the second, a conjoint plan with his workmate Edvaldo Pereira Paiva for the city entitled Contribuição ao estudo da urbanização de Porto Alegre, from 1938.

Keywords: History of town planning; plans; town planners. 


\section{Introdução}

A criação de planos que pretendiam organizar os espaços e as conexões entre indústria e habitação correspondeu a um grupo diferenciado no campo do urbanismo, dado que, o objetivo maior era o de estruturar, no período da industrialização brasileira, novos bairros e mesmo cidades voltadas para esta produção, considerada o novo vetor econômico do país. Em Porto Alegre, que viria a ser o principal pólo industrial do estado, as indústrias eram instaladas na periferia urbana ou junto às suas radiais de expansão e ligação para o interior, incentivando a produção de loteamentos próximos a estas radiais e configurando núcleos com características basicamente industriais e operárias que, ao longo do tempo, foram sendo integrados à cidade. ${ }^{1}$

Nesse contexto, este trabalho pretende analisar a trajetória e as idéias produzidas pelo engenheiro urbanista Luiz Arthur Ubatuba de Faria (1908 - 1954) para um plano de urbanização de um bairro industrial e operário em Porto Alegre plano esse encomendado pela iniciativa privada - mas que faria parte, a seguir, de outros trabalhos para a cidade, reiterando a idéia de um "plano de conjunto" preconizada pelo autor.

O engenheiro Ubatuba de Faria foi responsável por significativa contribuição no urbanismo que permanece ainda pouco explorada. Ele é considerado um dos pioneiros na construção e difusão do urbanismo como campo de saber no Rio Grande do Sul, e produziu trabalhos que vieram a influenciar os planos para a cidade de Porto Alegre. Um desses trabalhos, como veremos, foi a Contribuição ao estudo da urbanização de Porto Alegre (1938), elaborado em conjunto com seu colega - o urbanista Edvaldo Pereira Paiva. Os métodos de análise da cidade e, principalmente, a sua evolução urbana - estudados por Ubatuba de Faria - são temas já tratados em trabalhos de Rovati (2007) e Martins (2010); ambos destacam a noção que Ubatuba fazia de evolução urbana, questão fundamental para a compreensão da cidade e, a seguir, para a elaboração de um plano futuro.

No presente trabalho, no entanto, pretendemos fazer uma análise da fase inicial da produção deste urbanista gaúcho, especificamente sobre um de seus primeiros trabalhos profissionais na década de 30: o plano de um bairro industrial e operário a ser implantado em uma área de aproximadamente 700 hectares do município de Porto Alegre e na extensão do bairro industrial já consolidado. Tal trabalho destaca-se por

\footnotetext{
${ }^{1}$ A exceção, a ser destacada, seria a da Vila do Instituto de Aposentadoria e Pensões dos Industriários IAPI(1943), cujo projeto previa a construção de diferentes tipologias habitacionais para o operariado que seriam alugadas sob a coordenação do Instituto, órgão do Governo Federal.
} 
ser o primeiro de um grupo elaborado para uma mesma área, cujo objetivo de agregar habitação e indústria se perpetuou até a década de 60 e que, apesar de não haver obtido sucesso na sua implementação, é parte da história do urbanismo da capital, e pode explicar as funções características atuais da área em questão ${ }^{2}$.

Esse plano corresponderia não só a um dos primeiros trabalhos do urbanista, mas também a um reflexo prático de seu pensamento urbanístico e das idéias que o inspiraram. Como este projeto veio a fazer parte de um plano de conjunto para a cidade - a Contribuição, em 1938 - analisaremos ambos, considerando não somente a inserção do projeto do bairro industrial, mas também sua inserção no plano de conjunto.

\section{O Urbanista}

Luiz Arthur Ubatuba de Faria formou-se na Escola de Engenharia de Porto Alegre em 1932. Ainda como estudante, fez parte do quadro funcional da Prefeitura Municipal, na Seção de Cadastro. Em 1928, na administração Otávio Rocha (192428), assumiu o posto de topógrafo assistente, e acompanhou as obras realizadas nesta gestão e na seguinte de Alberto Bins (1928-37).

O engenheiro participava dos trabalhos de levantamento e cadastro da cidade e utilizava amplamente a fotografia como meio auxiliar na análise, interpretação e apresentação.

Rovati (2007) comenta que iniciou-se ainda em 1933 uma relação de amizade e colaboração entre Ubatuba de Faria seu colega na Seção de Cadastro - o Engenheiro Edvaldo Pereira Paiva - parceria que gerou alguns trabalhos conjuntos, como a Contribuição ao estudo da urbanização de Porto Alegre (FARIA, PAIVA, 1938).

Ainda em 1934, Ubatuba de Faria escreveu um artigo para o Boletim da Sociedade de Engenharia do Rio Grande do Sul intitulado Cadastro e Urbanismo em Porto Alegre, demonstrando a sua preocupação com o levantamento e cadastro da cidade e estudos diversos, inclusive o histórico, econômico e demográfico, com o objetivo de obter subsídios para a elaboração de um "plano de conjunto" para Porto Alegre (FARIA, 1934).

Nesse mesmo ano, como profissional autônomo, foi indicado pelo Engenheiro Geógrafo da Carta Geral da República Tito Marques Fernandes para a firma Mentz.

\footnotetext{
2 Nos referimos a "grupo" como o conjunto de outros projetos para a mesma área cujo objetivo era semelhante: Benópolis (1948) de autoria do Eng. Fernando Mendes Ribeiro e a Cidade Industrial de Porto Alegre (1961) de Edvaldo Pereira Paiva, Roberto Veronese e Marcos Hekman (MIRANDA, 2010).
} 
Quando contratado, elaborou alguns levantamentos das terras da firma e, em 1935, foi então convidado por esta para a elaboração de um plano para um bairro industrial e operário em uma extensa propriedade junto à confluência dos rios Gravataí e Guaíba - a chamada Várzea do Gravataí. Este trabalho, considerado por Ubatuba de Faria como "mais uma célula" em um plano de conjunto, foi incluído no trabalho da Contribuição ao estudo da urbanização de Porto Alegre em 1938, como parte do capítulo "Planos de Extensão". Ubatuba exaltou neste a importância das indústrias como "sustentáculos vigorosos do equilíbrio das finanças Municipais - o elemento cooperador por excelência" (FARIA, PAIVA, 1938: 114). Argumentava ainda que o incentivo no setor industrial representaria o equilíbrio social, o progresso e o bem estar. O discurso, neste caso, manifestava o seu discreto posicionamento com relação à doutrina positivista: a indústria era considerada um dos pilares da sociedade e era destacada por ele como o veículo responsável pela modernização e progresso e também garantidora da ordem social através do trabalho.

Como comentamos, Ubatuba de Faria exerceu um papel pioneiro na difusão do urbanismo como área do conhecimento no Rio Grande do Sul. Isto se deve não somente pelos seus artigos em jornais, mas também pelo evento da Exposição de Urbanismo realizada em 1936, tendo como responsáveis o próprio Ubatuba e seu colega Edvaldo Pereira Paiva. Tal evento apresentava, além dos diversos trabalhos da Diretoria de Cadastro, uma seção sobre a "Evolução da Cidade" e outra sobre o "Plano Geral de Urbanização de Porto Alegre" - ou o plano de conjunto. Na realidade, este plano correspondia a alguns projetos para a cidade e um plano de avenidas. Dentre os projetos, estavam apresentados o bairro industrial e operário na Várzea do Gravataí, o bairro residencial na Praia de Belas, a canalização do riacho, a entrada da cidade na chamada Ponta da Cadeia, o túnel sob a Rua Conceição e um parque náutico.

Destacamos que Ubatuba conheceu, nesses primeiros anos da década de 30, os planos de Francisco Prestes Maia para São Paulo - Estudo de um plano de avenidas para a cidade de São Paulo (1930) e o plano de Donat Alfred Agache para o Rio de Janeiro, intitulado Cidade do Rio de Janeiro, extensão, remodelação, embelezamento (1930) (Edvaldo Pereira Paiva: um urbanista, 1985:13). Tanto o trabalho de Prestes Maia como o plano Agache exerceriam grande influência - como veremos mais adiante - sobre o plano do bairro operário e na Contribuição elaborada com Paiva em 1938.

A questão da investigação e pesquisa da cidade tornou-se um dos elementos fundamentais nos trabalhos de Ubatuba, principalmente na análise do que ele chamou de evolução da cidade. Esta era parte significativa de suas pesquisas, sendo fartamente apresentada através de gráficos, estatísticas e fotografias comparativas. 
Colocava que "no estudo histórico e geográfico devem ser compilados todos os dados sobre a origem e o desenvolvimento da cidade", e que a estatística era especialmente necessária porque "devemos nos basear no passado para podermos prever o futuro" (FARIA, PAIVA, 1938:2).

Em 1937 foi contratado pelo Instituto Nacional de Estatística para fazer o levantamento aerofotogramétrico do Rio Grande do Sul. Transferiu-se para o Departamento de Balneários do Estado, elaborando também alguns planos para a iniciativa privada em praias do litoral norte do estado como Imbé, Atlântida, Tramandaí, Capão da Canoa e Cidreira (MARTINS, 2010:2).

Nos anos seguintes, a idéia do estudo do passado para a compreensão dos problemas do presente foi reforçada pelo artigo intitulado Evolução Urbana de Porto Alegre, em que Ubatuba de Faria utilizou o estudo da história da cidade e da sua geografia para mostrar o panorama futuro e as tendências do seu crescimento. 0 artigo fazia parte da publicação Porto Alegre: biografia de uma cidade (1940), um livro comemorativo dos 200 anos de colonização de Porto Alegre, organizado pela Prefeitura Municipal e apoiado pelo Governo do Estado e outras entidades.

As transformações da cidade foram fartamente ilustradas nesta publicação, destacando a evolução da mesma e as questões do urbanismo tão em evidência naquele período de modernização. Nesse sentido, Ubatuba de Faria sempre foi a favor da propaganda dos projetos e obras como meio de educar a população e de tornar pública a discussão sobre a cidade, reforçando que "urbanismo não se faz sem propaganda" e que, para que isso acontecesse, pretendia produzir conferências, exposições, notícias em jornais e até filmes (FARIA, 1935:1).

Esta questão da propaganda necessária do urbanismo e o discurso de Ubatuba de Faria nos indica que ele fazia coro às colocações do Engenheiro Luiz de Anhaia Mello, professor da Escola Politécnica de São Paulo, na sua publicação Problemas de Urbanismo, na qual, comentando sobre o plano de Chicago, argumentava que seus autores promoveram uma grande campanha na exposição do plano, no sentido de conquistar a opinião pública através de todos os meios ao seu alcance como jornais ilustrados, revistas, conferências e cartazes e que, em São Paulo, uma campanha deste tipo deveria ser implementada para a educação da sociedade (1929:20).

Consideramos que a posição de Ubatuba de Faria no que diz respeito à conquista do apoio da população para os planos urbanos é um dos aspectos que o destacam não só como um técnico consciente das dificuldades e dimensões da prática como também um urbanista difusor de seu campo, com vistas ao apoio necessário em todos os níveis. 
Em torno de 1942, realizou uma viagem de estudos ao Uruguai e visitou o Instituto de Urbanismo de Montevidéu conhecendo os professores daquela instituição: como Maurício Cravotto, um dos principais representantes do urbanismo sulamericano e experiente com as propostas de renovações urbanísticas européias e americanas ${ }^{3}$.

Ubatuba de Faria ainda faria parte do corpo docente do curso de especialização em urbanismo do Instituto de Belas Artes (IBA) e da Faculdade de Arquitetura criada em 1952, ministrando as disciplinas de Higiene da Habitação e Saneamento das Cidades.

Sua vida e trajetória, no entanto, foi interrompida precocemente aos quarenta e cinco anos de idade e em plena atividade profissional.

\section{A célula e o plano de conjunto}

Em 1934 a empresa Frederico Mentz S.A., com atuação em vários ramos da economia do estado, inclusive o industrial, contratou o urbanista Ubatuba de Faria para a elaboração de um plano de urbanização da área da Várzea do Gravataí, extensa área na zona norte de Porto Alegre na extensão dos bairros industriais Navegantes e São João e junto às principais conexões rodoviárias, ferroviárias e fluviais. Esse plano, que deveria abrigar indústrias e habitação operária, representava, segundo o seu autor, "o grande bairro industrial do futuro" (FARIA, 1936:51).

Este plano foi concluído em setembro de 1935 e, em 1938, como comentado, veio a fazer parte do trabalho da Contribuição ao estudo da urbanização de Porto Alegre como um dos planos de extensão da cidade, junto com o projeto do "Novo bairro residencial e Entrada da Cidade" de autoria de seu colega Edvaldo Pereira Paiva. A seguir analisaremos a colaboração do plano do bairro industrial na Contribuição.

O bairro industrial e operário 1935

Os planos da urbanização da Várzea do Gravataí tiveram origem em 1928, quando da aquisição da propriedade chamada de "Fazenda Gravathay", no quarto

\footnotetext{
${ }^{3}$ Conforme o jornal Correio do Povo de 21 de abril de 1949, os urbanistas Edvaldo Pereira Paiva e Luiz Arthur Ubatuba de Faria teriam se formado no Uruguai. Porém, segundo Almeida, a ida de Ubatuba de Faria para Montevidéu não pode ser comprovada pela falta de registros de sua passagem pelo Instituto de Urbanismo ou pela Faculdade de Arquitetura de Montevidéu, ainda que sua presença em Montevidéu se confirme em depoimento do arquiteto Demétrio Ribeiro, na ocasião estudante de arquitetura na mesma faculdade (2004:89).
} 
distrito de Porto Alegre, por um grupo de industriais - todos eles membros do que, segundo Singer, era "uma das mais importantes dinastias econômicas germano-riograndenses: Mentz, Marquadt e Trein" (1977:165). A propriedade era constituída por uma área de aproximadamente 700 hectares junto aos rios Guaíba e Gravataí e sujeita a frequentes inundações nos períodos de cheias; porém, configurava posição estratégica do município com conexões com os rios, estradas e via férrea.

Tal área era sempre referida nas atas da empresa Mentz como o "imóvel do Gravataí" e destacava-se em relação aos demais imóveis e loteamentos desta firma 4 . Não conhecemos as razões pelas quais esta propriedade teve uma consideração especial em relação aos demais empreendimentos da firma. Podemos supor que esta tomada de decisão deu-se, primeiro: pelas consideráveis dimensões da área, se a observarmos comparativamente aos limites urbanos da cidade de Porto Alegre da época; segundo, pela intenção, firmada entre os sócios, da elaboração de um audacioso plano que contemplasse a habitação operária e a indústria, atividades que viriam a reforçar e ampliar a tendência industrial dos bairros da zona norte.

Como já citado, o Engenheiro Luiz Arthur Ubatuba de Faria foi indicado, em 1934, pelo Engenheiro Tito Marques Fernandes, sugerindo que "Ubatuba era um excelente urbanista e que a firma não necessitaria da contratação de profissionais estrangeiros para a elaboração do plano" (Atas da Empresa F. Mentz, n¹34 de 13/11/1933). Consta ainda que, em ata da firma datada de 1934, a encomenda do trabalho foi feita ao "Dr. Ubatuba de Faria, que conjuntamente com o Dr. Benno Hoffman e o Coronel Tito Marques Fernandes, nos apresentarão em breve um anteprojecto" (Atas da Empresa F. Mentz, nº188 de 20/11/1934). Este comentário é significativo, pois Benno Hoffmann era um engenheiro formado na Alemanha que estudou, com renomados sanitaristas alemães como Brix e Genzmer, sobre as obras de Camilo Sitte, Hénard, Stüebben, Brown e Saturnino de Brito, influenciando por certo o jovem colega Ubatuba de Faria no projeto do bairro industrial e operário (WEIMER, 2004:87).

Na apresentação do trabalho chamado de Projecto de um plano de urbanização para um bairro industrial e operário na Várzea do Gravatahy, entregue à empresa em setembro de 1935, Ubatuba de Faria comentou o tamanho de sua incumbência:

A importância e envergadura da tarefa não permitiam que nos restringíssemos ao projecto local e nos obrigou a abarcar uma vasta zona da

\footnotetext{
${ }^{4}$ A firma Frederico Mentz S.A. funda uma sociedade especificamente para a exploração e loteamento de seus imóveis a "Urbanizadora Mentz". O "Imóvel do Gravataí" não fazia parte das propriedades desta urbanizadora. Atas da Firma F. Mentz S.A.
} 
cidade, cuidando muito especialmente do traçado das futuras avenidas, que ligarão o centro urbano ao bairro industrial projectado.

Sem este prévio estudo, que a primeira vista, parece desnecessário, o trabalho pecaria pelo que tem de fundamental, isto é, a sua continuidade para o futuro (FARIA, 1935:1).

Estabeleceu-se também nesta apresentação do trabalho um acordo tácito entre as partes envolvidas no plano: o urbanista buscaria a promoção do trabalho e um possível apoio da esfera pública, esclarecendo que tal plano havia sido exposto na sede da Sociedade de Engenharia do Rio Grande do Sul e que ele, como técnico, não pouparia esforços neste tipo de realização:

A exposição do plano [...] interessou os técnicos ligados directamente aos problemas de urbanismo de Porto Alegre, e nós cremos que isto significa o primeiro passo seguro para a realização futura. [...]

Estamos directamente ligados, pelos laços de classe e pela função pública a tudo quanto se refere - PORTO ALEGRE MAIOR E MELHOR - e assim sendo, como idealista e technico não pouparemos esforços em prol das realizações de envergadura, que transformarão a capital do Rio Grande do Sul em uma cidade digna do nosso progressista Estado (FARIA, 1935:1).

A partir disso, Ubatuba de Faria se compromete com os sócios e especifica a questão da promoção do plano, argumentando que seriam utilizados filmes, projeções, pranchas demonstrativas, noticiários em jornais e conferências para tornálo público (FARIA, 1935:1).

No esclarecimento deste trabalho, em palestra para os técnicos na Sociedade de Engenharia do Rio Grande do Sul e no artigo produzido para o seu Boletim em 1936, intitulado Urbanização da Várzea do Gravataí - o autor reproduziu praticamente todo o material iconográfico do plano apresentado para a firma e um filme sobre a cidade e a nova área a ser urbanizada (FARIA, 1936).

O plano como documento para a firma, além dos comentários introdutórios, era organizado em: Relatório, Porto Alegre histórico, Plano das Novas Avenidas, Trânsito Urbano, Bairro Industrial e Operário na Várzea do Gravatahy e o seu projeto, que foi dividido em duas grandes zonas - a industrial portuária e a residencial.

Constava na descrição do plano que a cidade comportaria "um grande bairro industrial e operário do futuro", e que este seria mais uma "célula" dentro de um "plano de conjunto" para a cidade (FARIA, 1936:89). É fato que a grande extensão de terra contemplada pelo projeto e a importância das conexões com os rios, estrada e ferrovia exigiriam do seu autor o planejamento das relações com a cidade e a região; o projeto não poderia ser considerado da mesma forma que os vários loteamentos para habitação que surgiam afastados do centro. 
Reforçando e fundamentando sempre o valor deste trabalho para a cidade, Ubatuba de Faria desenvolve o plano em duas partes:

a) a histórico-evolutiva: utilizando-se de mapas progressivos, fotos e quadros estatísticos em que demonstra o crescimento da cidade.

b) a do sistema viário e conexões externas: possíveis ligações com municípios vizinhos, ressaltando a importância desta área para o escoamento da produção colonial. (Estrada de ferro para Santa Maria e São Leopoldo). Necessidade de uma trama de novas avenidas, chamado de "Plano de Novas Avenidas", que ligasse a área central à Várzea, devido ao movimento crescente de veículos e a demanda de ampla ligação com o bairro. Incluiu outras propostas de traçados para a cidade, a ampliação na largura de vias e a construção de um túnel sob a Rua da Conceição.

O plano era, portanto, bem mais abrangente que o projeto do bairro industrial e operário encomendado, aprofundando-se em uma análise que embasava o trabalho através da evolução e estatísticas da cidade - em novas proposições estruturais, como a trama de novas avenidas que canalizariam o tráfego para a zona da Várzea e para as rotas para fora do município; o "plano de conjunto" que articularia um projeto de extensão da cidade (Fig.01).

O "Plano de Novas Avenidas" proposto ligaria o centro ao novo bairro, e tinha o objetivo de alargar e estender ruas existentes, melhorando o tráfego e tornando-se vias de ligação rápida para uma zona onde, segundo o autor, se estenderia Porto Alegre futuro. As avenidas, portanto, seriam uma trama de quatro: Avenida Farrapos, ligação Farrapos - Minas Gerais, Avenida Minas Gerais e ligação Minas Gerais com a Estrada Passo d'Areia. Como o próprio nome sugeria, este plano reflete as preocupações que, em maior escala, decorreram na proposição do Plano de Avenidas para a cidade de São Paulo de Francisco Prestes Maia na remodelação e extensão do seu sistema

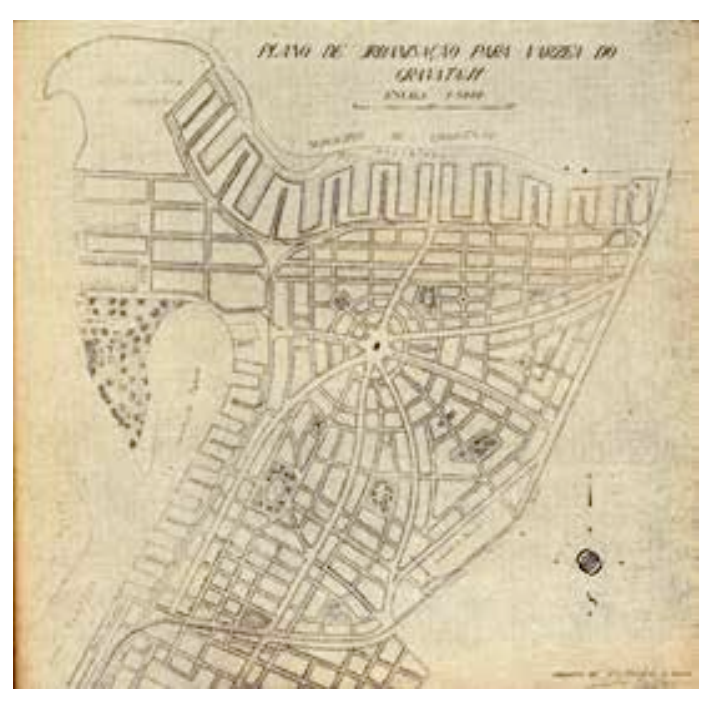

Fig. 01: Plano de Urbanização para a Várzea do Gravataí, 1935. Fonte: Boletim da Sociedade de Engenharia do Rio Grande do Sul $n^{\circ} .15,1936$. viário.

O plano de avenidas inicialmente proposto por Ubatuba de Faria no plano do bairro industrial e operário seria ampliado no trabalho da Contribuição, finalmente 
fazendo parte de um esquema de novas avenidas que organizaria todo o tráfego a partir da península do centro da cidade e as ligaria através de perimetrais, em uma associação semelhante ao sistema radial-perimetral proposto por Prestes Maia.

A preocupação com o tráfego, como vimos, foi um dos aspectos da proposta de plano de conjunto que embasariam o projeto do bairro. Por outro lado, a configuração do Projecto era, no que se refere ao traçado e à sua descrição, uma nova extensão para a cidade, com conceitos e referências - que o precederam - tanto do urbanismo europeu como do Brasil. A exemplo de outros planos de extensão urbanos do início do século XX na Europa e nos Estados Unidos, o plano da Várzea previa um extenso bairro novo, com a utilização do zoning como princípio da organização do espaço e a integração do mesmo no tecido da cidade. A noção de zoning citado neste plano por Ubatuba de Faria foi difundida por Agache em 1930, na remodelação da cidade do Rio de Janeiro: dever-se-ia reconhecer a existência de certos elementos funcionais particulares da cidade e distribuí-los da melhor forma, o que se denominava zoning ${ }^{5}$. O princípio e a finalidade buscados pelo zoning exigiam uma nítida separação entre os bairros residenciais, comerciais e industriais, o que permitiria, a partir desta separação, definir os níveis de intervenção sobre a cidade (AGACHE, 1930).

No plano do bairro industrial, o seu autor organiza o zoning em duas funções principais: a industrial portuária, junto aos rios Guaíba e Gravataí, e a de habitação. A primeira seria uma ampla faixa atendida por docas e rede ferroviária de escoamento; a segunda, referente à zona de habitação, seria separada pela linha férrea principal, a de manobras e as avenidas de maior tráfego, que acabariam por formar segmentos de habitação com praça, escola e quadra comercial chamados por Ubatuba de "centros com vida própria" (FARIA, 1935:33). Consideramos que a proposição de tais segmentos - ou centros -descritos no projeto teria conceito semelhante ao de unidade de vizinhança difundido por Clarence Arthur Perry, na monografia The Neighborhood Unit que integrava o plano de Nova York editado entre 1923 e 1929 e utilizado amplamente no desenvolvimento das novas áreas suburbanas dos Estados Unidos ${ }^{6}$. A unidade de vizinhança neste caso seria limitada pelo raio de distância até a escola primária, e o sistema de vias internas deveria ser traçado de modo a desencorajar a circulação de passagem, com ruas de pouco volume de tráfego (PERRY,1929).

\footnotetext{
${ }^{5} \mathrm{O}$ instrumental do zoning planing (teoria do zoneamento urbano) foi proposta originalmente por Franz Adikes prefeito de Frankfurt em 1893 com o objetivo de controlar as rendas fundiárias urbanas e o valor do solo urbano (COSTA, 2003:105).

${ }^{6}$ Este plano chamou-se Regional Plan of New York and its environs sob a coordenação de Thomas Adams. A seguir, Clarence Stein e Henry Wright a fazem a primeira aplicação da idéia no plano urbano de Radburn, Nova Jersey, em 1929, coincidentemente o ano da publicação da monografia de Perry, onde inclusive constam ilustrações do plano de Radburn (BARCELLOS, s/d).
} 
Os centros de habitação propostos não foram detalhados no projeto, impossibilitando-nos de avaliar a proximidade destes com a unidade de vizinhança de Perry. No entanto, podemos inferir que Ubatuba tivesse tido neste caso alguma influência dos modelos alemães de Cidade-jardim e moradia operária: os siedlungen ${ }^{7}$. Neles, propunham-se espaços coletivos com equipamentos como escolas, lavanderias coletivas e algum comércio de primeira necessidade, propondo uma associação direta com o caso do bairro industrial.

No zoneamento residencial foi projetado um largo de forma elíptica com eixos de 300 e 200 metros. Para este largo, confluiriam as avenidas principais do plano de avenidas com 30, 40 e 50 metros de largura e amplo raio de curvatura. Naquele se localizaria o centro cívico com agências de correio, filiais de bancos, cartórios, departamentos da prefeitura, cafés, bares e cinemas.

A localização e articulação das duas grandes zonas industrial e residencial trazem a associação formal ao modelo de cidade-jardim de Ebenezer Howard: as avenidas radiais, os anéis de indústrias viação férrea, o centro cívico e comercial em torno grande elipse (fig. 02). A proposição de jardins internos aos quarteirões de habitação descritos no plano remete aos jardins comuns das cidades-jard Barry Parker em São Paulo ${ }^{8}$.

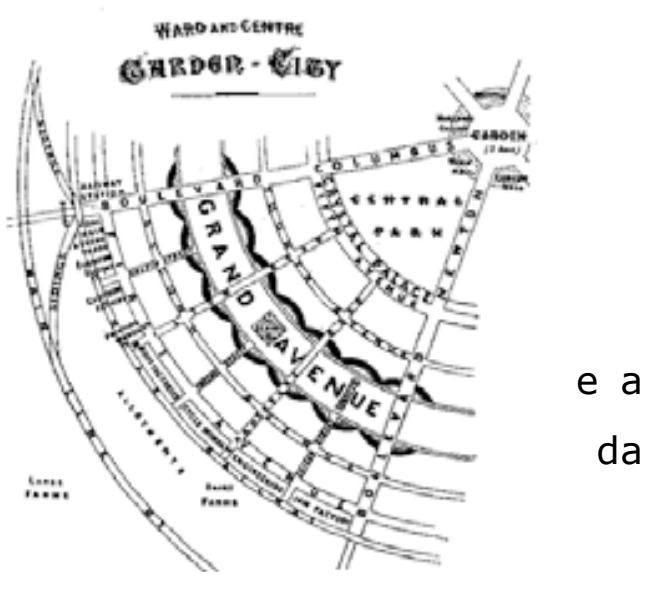

Fig.02: Modelo Cidade-jardim de E. Howard. Fonte: HOWARD, , de
1996.

O traçado da zona industrial seria periférico ao resıdencıal, com suas ruas retas de largura mínima de 20 metros, com grande parte dos lotes sendo servidos por linhas férreas para vagões e alinhados às docas particulares reentrantes ao longo dos rios. A área dos lotes junto ao rio Gravataí foi parcialmente detalhada - detalhamento esse que demonstrou as conexões que haveriam entre as docas, o lotes, a rua interna e a linha de vagões, facilitando a carga e descarga. O cuidado com a direção dos ventos no projeto - objetivando evitar as contaminações do ar - remete aos mesmos cuidados que a Cidade Industrial de Tony Garnier elaborada ainda em 1904.

Os parques públicos para cidades industriais na primeira metade do século XX tinham como finalidade principal provê-las de ambientes naturais higienizadores e

\footnotetext{
${ }^{7}$ Os siedlungen alemães foram financiados pelo Estado Alemão através de cooperativas e sindicatos entre 1918-1933 e as idéias de cidades-jardim estavam presentes na qualificação da moradia operária, conjugando-se também com idéias racionalistas (Cidades jardins,1997).

${ }^{8}$ O bairro Jardim América era de 109 hectares e foi loteado em 1913 com projeto de Barry Parker e Raynond Unwin. O loteamento-jardim, não tinha a auto-suficiência da Cidade-jardim, sendo mais próximo a um subúrbio com alguma infra-estrutura (HOWARD, 1996:71).
} 
promover, como disse Choay, "a moralização da classe trabalhadora, tão sufocada pela realidade da industrialização dos espaços urbanos" (1994:61). No plano do bairro operário, seu autor introduziu esta idéia destacando o valor sanitário e social dos parques e reservando um trecho em península junto ao Saco do Cabral no Guaíba para um "parque com uma situação magnífica, com água pelos dois lados" (FARIA, 1935:34).

A execução do projeto começou em 1938, com as obras de aterro da Várzea e a abertura de um canal mestre para o saneamento da área. A iniciativa do projeto e o início dos trabalhos foram divulgados em jornal local ainda no final de 1937, comentando os benefícios do empreendimento e prevendo que o tempo para a execução do projeto de urbanização seria de aproximadamente dez anos (Diário de Notícias, 11/12/1937). Porém, segundo ata de reunião da firma de junho de 1941, devido aos danos da enchente sofrida no mesmo ano, foi decretada a "inutilidade de todo o serviço de urbanização". Como os custos foram de grande monta para a empresa, os sócios resolveram por terminar definitivamente as obras com a venda da draga, bomba de sucção, canos e trilhos (Ata da Empresa F. Mentz, n510 de 23/06/1941).

A Contribuição ao estudo da urbanização de Porto Alegre 1938

Depois do Plano Geral de Melhoramentos de Porto Alegre de João Moreira Maciel aprovado em 1914 e, mais precisamente, a partir da administração Otávio Rocha (1924-28), a Prefeitura Municipal passou a implementar grandes obras públicas que estruturavam principalmente o seu centro. Na administração Alberto Bins (1928-37) ampliou-se a cidade, principalmente ao longo das suas principais radiais, e prosseguiram as obras iniciadas na gestão anterior e as novas, focadas no saneamento.

É neste período que os engenheiros Luiz Arthur Ubatuba de Faria e Edvaldo Pereira Paiva começaram a discutir os problemas da cidade e a elaborar estudos e projetos que inicialmente viriam a fazer parte da Exposição de Urbanismo em 1936 e, depois em 1938, no trabalho intitulado Contribuição ao estudo da urbanização de Porto Alegre.

O estudo da Contribuição era composto por nove partes, além de uma introdução: A evolução da cidade de Porto Alegre (I), As linhas gerais do Plano Diretor (II), O Plano de Avenidas (III), os Planos de Extensão (IV), Espaços Livres (V), Parque Náutico (VI), O Problema das Enchentes (VII), Canalização do Riacho (VIII), O 
problema do tráfego (IX), todas elas subdivididas em capítulos. Não temos o objetivo, neste trabalho, de elaborar uma análise de todas estas partes ou mesmo de nos aprofundarmos na análise da Contribuição, já tratada por outros autores ${ }^{9}$.

Pretendemos destacar no entanto, as contribuições de método e estudos prévios de Ubatuba de Faria para o plano do bairro industrial e operário que vieram a fazer parte da sua idéia de plano de conjunto da cidade, organizado finalmente na Contribuição.

Os engenheiros e colegas na Divisão de Cadastro da Prefeitura partiram do conhecimento de duas obras do período: Estudo de um Plano de Avenidas para a cidade de São Paulo de Francisco Prestes Maia (1930) e Cidade do Rio de Janeiro, extensão, remodelação, embellezamento, de Alfred Donat Agache (1930). Além destes trabalhos como referencial, os urbanistas organizaram a sua base de pesquisa - os levantamentos da seção de Topografia da Diretoria de Cadastro e as análises baseadas nas estatísticas e nas fotografias que construíam um panorama evolutivo da capital.

A proposta do Plano de Avenidas - a questão central do trabalho - pretendia descentralizar o centro da cidade e fazer a distribuição do tráfego através do chamado "perímetro de irradiação": anéis concêntricos de vias a quatro e oito quilômetros do centro que fariam a ligação das suas radiais em forma de leque a partir da península.

O modelo então formado foi chamado de Esquema Teórico de Porto Alegre (fig.03) - um diagrama de radiais e perimetrais. Os autores citaram no trabalho o urbanista francês Eugene Hénard como o pioneiro na proposição do perímetro de irradiação como meio de regular o trânsito convergente. Prestes Maia também usou tal modelo em 30, com mesmo nome e com semelhanças aos modelos de Hénard para as cidades de Moscou, Berlim e Paris; o Plano de Avenidas de São Paulo foi confirmado, pelos autores da Contribuição, como a

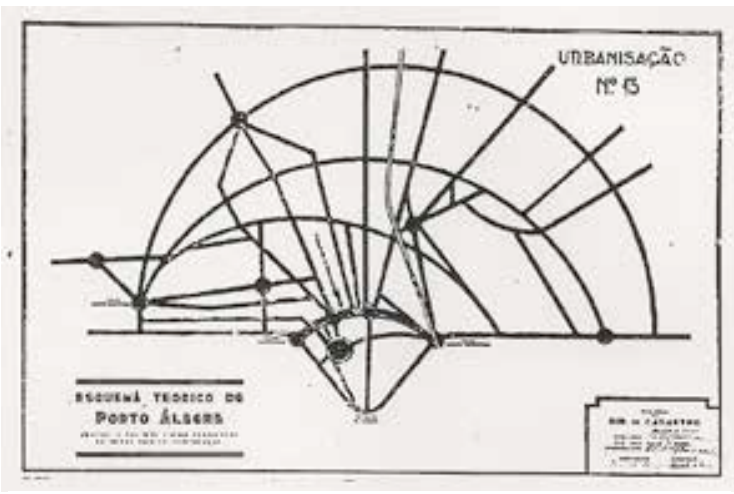

Fig 03:Esquema teórico de Porto Alegre. Plano de Avenidas. Fonte: FARIA, PAIVA, 1938.

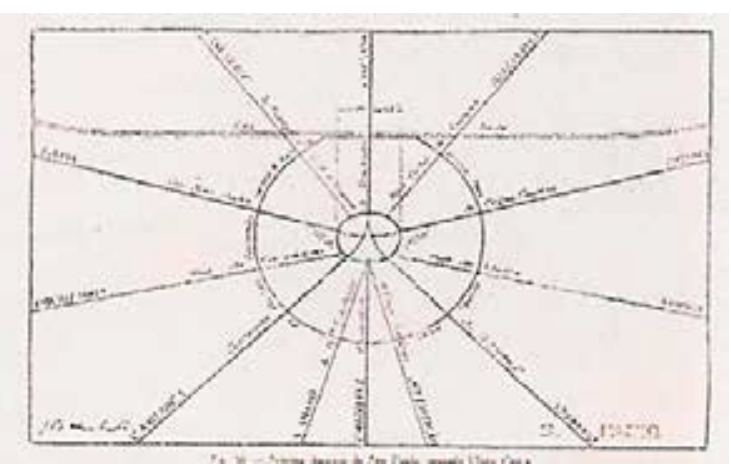

\footnotetext{
${ }^{9}$ ABREU FILHO, 2010.
} 
referência mais direta (fig.04).

Destacamos que foi preservado no Esquema Teórico de Porto Alegre, o Fig. 04: Modelo do Perímetro de Irradiação de Prestes Maia para o Plano de Avenidas conjunto das novas avenidas já projetadas de São Paulo. Fonte: MAIA, 1930. no plano do bairro industrial e operário. No Esquema, as novas perimetrais convergiriam todas para as avenidas do bairro industrial, em uma centralização de vias rápidas na zona norte da cidade (encontro dos do semi-círculos fig.03).

A pesquisa sobre a cidade e sua evolução correspondeu também a um outro aspecto fundamental do plano do bairro que foi retomado na Contribuição: o método de abordagem da cidade. O capítulo Porto Alegre Histórico, que continha mapas, estatísticas e fotografias tratados analiticamente por Ubatuba foi retomado à semelhança na Contribuição, na parte chamada de Evolução da Cidade de Porto Alegre, que continha os seguintes capítulos: Os componentes antropogeográficos (I) e $A$ análise da situação urbana (II) (FARIA,PAIVA, 1938). No plano do bairro industrial e operário, as fotografias foram um recurso bem mais utilizado, não só para refletir o progresso por meio de comparação, mas também para o estudo das novas avenidas projetadas e do túnel da Conceição. Naquelas, foram mostradas as condições das vias na época, fundamentando em que casos seriam necessárias as desapropriações e em quais seriam feitos os recuos progressivos para a implantação. O argumento de organizar as avenidas na direção do bairro industrial e operário era de que, para esta zona, convergiria o desenvolvimento da cidade, já servida pela linha férrea e estradas, podendo contar ainda com um trem suburbano que serviria o bairro e as vilas que tinham urbanização crescente do outro lado do rio Gravataí, no município de Canoas.

Ainda que as fotografias referentes às avenidas do plano do bairro operário de Ubatuba de Faria não fossem anexadas integralmente, o seu traçado foi introduzido plenamente no modelo teórico do Plano de Avenidas de Porto Alegre. Como parte das soluções de tráfego havia ainda o Túnel da Conceição, cujo projeto proposto por Ubatuba no plano do bairro foi incluído no capítulo do perímetro de irradiação.

Obviamente, a Contribuição foi um trabalho de dois autores que elaboraram seus projetos anteriores considerando-os como parte de um plano de conjunto e de uma discussão sobre os dados a que tinham conhecimento na Prefeitura. A introdução de seus projetos, como o do Bairro industrial e operário no caso de Ubatuba de Faria e o Novo bairro residencial e Entrada da Cidade de Edvaldo Pereira Paiva propuseram o desenvolvimento de áreas fora do centro - os planos de extensão, destacando a singularidade da Contribuição no sentido da expansão da cidade, aspecto que só seria 
novamente contemplado no Ante-projeto de planificação de Porto Alegre em $1951^{10}$. Consideramos clara a decisão dos autores do trabalho sobre questões fundamentais relativas à infraestrutura de Porto Alegre como, por exemplo, da localização e expansão do seu porto para a zona norte, junto ao bairro industrial. Este assunto era ponto de divergências no período, com alguns técnicos defendendo a expansão para o sul, enquanto os industriais propunham o oposto ${ }^{11}$.

O porto na zona norte era considerado a alternativa mais apropriada para Ubatuba no projeto do bairro, pois, na configuração da zona industrial, ele articulou docas reentrantes para acesso dos navios e propôs a desobstrução de parte do rio Guaíba para comportar navios de até 17 pés.

\section{O discurso e os reflexos}

As condições que envolvem a elaboração dos dois trabalhos aqui analisados também devem ser comentadas. Na origem do projeto do bairro industrial e operário estavam os interesses da indústria, representada pelos seus contratantes que, com o objetivo de agregá-la à habitação operária, pretendiam a urbanização de uma extensa propriedade. Ressaltamos ainda que, como a maioria do empresariado industrial porto-alegrense, a Firma Mentz tinha origem germânica e, portanto, fortes laços com a classe industrial que ambicionava a estruturação do setor na Capital.

O urbanista Ubatuba de Faria fora contratado inicialmente, como comentamos, conjuntamente com o urbanista Benno Hoffmann e o Engenheiro Tito Marques Fernandes, sendo este último encarregado do levantamento da propriedade. No entanto, em 1934, Hoffmann se desligou da incumbência, devido ao início de seus trabalhos como chefe da Diretoria de Obras da Barra de Rio Grande ${ }^{12}$.

Ubatuba de Faria, como técnico da Divisão de Urbanismo, pensou e articulou o Plano do bairro industrial e operário como parte de um plano de conjunto para a cidade - a futura Contribuição - que vinha sendo discutido na mesma época com seu colega Edvaldo Pereira Paiva. Estas duas situações, o bairro e o plano de conjunto que resultaria na Contribuição, dividem o plano: uma era a análise histórico-evolutiva e o plano das novas avenidas para a cidade, que fariam a ligação com o bairro; outra,

\footnotetext{
${ }^{10}$ O Ante-projeto de planificação de Porto Alegre foi uma proposta pautada nos princípios da Carta de Atenas, considerando as principais funções da cidade: habitação, circulação, trabalho e recreação. Este plano serviu de base para planos posteriores da cidade (PAIVA, 1951).

${ }^{11}$ Sobre esta discussão ver PORTO, 1938.

${ }^{12}$ Conforme atas da firma que trataram sobre o projeto do bairro operário a partir de 1935, o Engenheiro Benno Hoffmann não era mais citado e consta que, em 1934, assumiu como chefe da seção da Diretoria de Obras da Barra de Rio Grande (WEIMER, 2004:87).
} 
mais restrita e objetiva, era a extensão da cidade, o projeto do bairro modelo agregando a indústria e a habitação.

A área relativa ao projeto era de grandes proporções. A empresa, receosa do tamanho do seu investimento, viu na afirmação de Ubatuba - "Urbanismo não se faz sem propaganda" a divulgação do projeto, e possivelmente, o apoio de outras esferas (FARIA, 1935:1). Isso foi comentado pela firma já em 1936, quando relatam que o engenheiro Ubatuba de Faria "iniciou a propaganda pelo Correio do Povo e é de esperar que o município e o Governo do Estado voltem suas vistas para um projeto como este" (Atas da Firma Mentz, 07/04/1936).

Apesar de Porto Alegre ter na época um prefeito pertencente à classe industrial como era Alberto Bins, o apoio esperado não veio, e a empresa iniciou por sua conta e risco as obras de urbanização em 1938. A enchente de 1941 acabou causando grandes prejuízos à urbanização, inviabilizando a sua continuidade (Atas da Firma Mentz, 23/06/1941).

Como comentamos acima, a primeira parte do plano - a histórico-evolutiva - e o plano de avenidas foram incluídos no plano de conjunto ou Contribuição ao estudo da urbanização de Porto Alegre. Em 1936, Ubatuba divulga o trabalho do bairro operário "do futuro" em um artigo no Boletim da Sociedade de Engenharia do Rio Grande do Sul e sugere, no final de seu texto, que: "o projeto pede o auxílio dos técnicos especializados e nós contamos com a crítica constructora para corrigir os erros e melhorar a obra concebida" (1936: 95). Ele expõe, portanto, uma análise precedente para o plano de conjunto que, através da propaganda do plano do bairro operário, alcançaria o meio técnico e incitaria uma discussão sobre a cidade.

No final de 1938, porém, o então prefeito Loureiro da Silva encarregou o arquiteto paulista Arnaldo Gladosch - colaborador da equipe de Agache no Rio de Janeiro - para a elaboração de um plano diretor para Porto Alegre, amplamente discutido nas reuniões do Conselho do Plano, mas nunca efetivamente completado.

Nos anos seguintes, Paiva faz a autocrítica do trabalho da Contribuição na sua palestra do Instituto de Belas Artes e no título Problemas Urbanos de Porto Alegre especificamente no capítulo "Tentativas de planificação urbana" (PAIVA, 1951). Ele argumenta que, no trabalho da Contribuição, a solução do Perímetro de Irradiação (fig.03) foi limitada, percebendo tão somente o aspecto viário e desconsiderando a questão do zoneamento. Ainda criticou os projetos de extensão elaborados por ele e Ubatuba dizendo que: 
Qualquer um desses projetos, apesar de conter aspectos positivos, sofria de graves defeitos, provenientes do nível de então de nossos conhecimentos urbanísticos. Nos dois projetos se observa: uma excessiva centralização do tráfego sobre determinados pontos, excessivo monumentalismo e divisão inadequada dos espaços (PAIVA, 1951:12).

No entanto, na parte intitulada "Situação atual" Paiva retoma os projetos de extensão que fizeram parte da Contribuição, em um estudo que, segundo ele, foi proposto para alunos do curso de arquitetura do Instituto de Belas Artes com a sua colaboração. Na experiência de estudo referente ao bairro industrial, agora protegido pelo dique de cintura e ampliado na direção do Navegantes, propõe um zoneamento de atividades que permanece muito semelhante ao do plano de 35 , ou seja, a faixa industrial é periférica às unidades habitacionais do centro, separada por um parque linear. O centro cívico ainda era centralizado estrategicamente na curva do dique, mas sem a confluência de avenidas de tráfego rápido do primeiro projeto de Ubatuba (fig.05). O plano do bairro industrial e operário de Ubatuba continuava portanto, a ser uma referência inequívoca.

A questão da indústria e da habitação ainda permanece um plano a empreendido em Porto Alegre e, em 1961, foi a vez do Governo de Estado elaborar uma proposta para a Várzea do Gravataí: a Cidade Industrial. Os seus

Fig.05: Projeto de "uma nova cidade" (1951) - (Estudo) Eng. Edvaldo Pereira Paiva.

Fonte: PAIVA, 1951 autores foram Roberto Veronese, Marcos Hekman e o urbanista Paiva, que participou também da elaboração da Política de Industrialização, dentro de uma meta desenvolvimentista do Estado voltada para a indústria (PAIVA, 1961). A área abrangida por este trabalho foi ampliada na direção leste, mas ainda assim o zoneamento permaneceu similar ao do plano Ubatuba. Os "centros de vida própria", originalmente propostos no plano do bairro, tornam-se, na Cidade Industrial, as "unidades vicinais", e a linha ferroviária continuaria neste projeto, separando a zona residencial da industrial.

Finalmente, esses projetos não foram implementados pelas mais diversas razões, que não discutiremos neste trabalho. Apesar disso, como visto, os planos do urbanista Ubatuba de Faria abordados representam, no estudo do urbanismo, um período de idéias e conceitos semelhantes presentes também no contexto brasileiro. Além de publicações como os planos de São Paulo e Rio de Janeiro, Ubatuba sofreu 
influência direta de seus colegas: do engenheiro Benno Hoffmann, cuja formação no urbanismo alemão teve reflexos sobre o projeto do bairro, e do engenheiro Edvaldo Pereira Paiva, com quem realizou pesquisa e estudos em conjunto.

O mais importante a ressaltar, no entanto, é que urbanistas como Ubatuba de Faria foram pioneiros na pesquisa, análise da cidade e divulgação do urbanismo como campo de conhecimento no Rio Grande do Sul. Os seus planos aqui abordados fundamentais no quadro evolutivo do pensamento urbanístico - revelam as suas ressonâncias em Porto Alegre se considerarmos que seus estudos vieram a ser retomados em planos posteriores para a cidade.

\section{Referências}

ABREU FILHO, Silvio B. de (2010). Urbanismo às margens : revendo a "Contribuição ao estudo da urbanização de Porto Alegre" [recurso eletrônico]. In: XI Seminário de História da Cidade e do Urbanismo, Vitória.

AGACHE, Alfred Donat (1930). Cidade do Rio de Janeiro: extensão, remodelação, embellezamento. Paris: Foyer Brasilien.

ALMEIDA, Maria S.(2004). Transformações urbanas: atos, normas, decretos, leis na administração da cidade de Porto Alegre 1937/1961. São Paulo: Faculdade de Arquitetura e Urbanismo, USP. (Tese de Doutorado).

BARCELLOS, Vicente Q. Unidade de Vizinhança: notas sobre sua origem, desenvolvimento e introdução no Brasil. Disponível em: http://vsites.unb.br/fau/pos_graduação/paranoa/edicao2001/unidade/unidade.htm acesso em: 09.01.2011

Cidades jardins: a busca do equilíbrio social e ambiental 1898-1998 (1997). São Paulo: Fundação Bienal de São Paulo, FAUUSP.

CHOAY, Françoise (1994). La naturaleza urbanizada. DETHIER, Jean.; GUIHEUX. Alain (org.) Visiones urbanas. Europa 1879-1993. Barcelona: Electa/CCCB, p. 61-66.

COSTA, Luiz A. M (2003). O ideário urbano paulista na virada do século: 0 engenheiro Theodoro Sampaio e as questões territoriais e urbanas modernas. 18861903. São Carlos: RiMa, FAPESP.

Edvaldo Pereira Paiva: um urbanista (1985). Porto Alegre:UFRGS/IAB/RS.

PERRY. Clarence Arthur (1929). The Neighborhood unit. In: Regional Plan of New York and its Environs, Regional Survey, volume VII, New York. 
FARIA, Luiz Arthur Ubatuba de (1934). Cadastro e urbanismo. In: Boletim da Sociedade de Engenharia do Rio Grande do Sul. N ${ }^{\circ} 6$, jan. p.32-41.

FARIA, Luiz Arthur Ubatuba de (1936). Urbanização da Várzea do Gravataí. In: Boletim da Sociedade de Engenharia do Rio Grande do Sul. Nº15, jan.,p.51-95.

FARIA, Luiz Arthur Ubatuba de., PAIVA, Edvaldo Pereira (1938). Contribuição ao estudo da urbanização de Porto Alegre. Porto Alegre: Secretaria de Planejamento Urbano.

FARIA, Luiz Arthur Ubatuba de (1940). A evolução urbana de Porto Alegre. In: FRANCO, Álvaro (org). Porto Alegre, biografia de uma cidade. Porto Alegre: Tipografia do Centro, p.344-353.

GARNIER, Tony (1989). Une cite industrielle: etude pour La construction des Villes. New York: Princenton Arch.

HOWARD, Ebenezer (1996). Cidades-jardins de amanhã. São Paulo: HUCITEC Ltda.

LEME, Maria Cristina da Silva (1999). Urbanismo no Brasil 1895-1965. São Paulo: Studio Nobel; FAUUSP; FUPAM.

MAIA, Francisco Prestes (1930). Estudo de um Plano de Avenidas para a cidade de São Paulo. São Paulo: Companhia de Melhoramentos de São Paulo.

MARTINS, Thaís M. B (2010). Evolução Urbana por Ubatuba de Faria [recurso eletrônico]. In: XI Seminário de História da Cidade e do Urbanismo [recurso eletrônico], Vitória.

MELLO, Luiz Ignácio R. de Anhaia (1929). Problemas de urbanismo: bases para a resolução do problema technico. São Paulo: Escolas Profissionais Salesianas.

MIRANDA, Adriana E. (2010). O ideal urbano-industrial: os projetos para a Várzea do Gravataí em Porto Alegre. [recurso eletrônico] In: XI Seminário de História da Cidade e do Urbanismo. [recurso eletrônico], Vitória.

PAIVA, Edvaldo Pereira; RIBEIRO, Demétrio. (1951). Problemas urbanos de Porto Alegre. Porto Alegre: Prefeitura Municipal de Porto Alegre.

PORTO, Jorge (1938). Problemas urbanos de Porto Alegre. In: Boletim da Sociedade de Engenharia do Rio Grande do Sul. №25, pp.95-130.

ROVATI, João F. (2007). Caminhos da evolução urbana [recurso eletrônico]. In: XII Encontro da Associação Nacional de Pós-Graduação e Pesquisa em Planejamento Urbano e Regional, Belém, Anais [recurso eletrônico], UFPA. 
SITTE, Camilo (1992). A construção das cidades segundo seus princípios artísticos. São Paulo: Ática.

WEIMER, Günter (2004). Arquitetos e Construtores no Rio Grande do Sul 18921945. Santa Maria: Ed. UFSM.

\section{Periódicos:}

O $90^{\circ}$ aniversário de fundação da Firma Frederico Mentz: será executado o plano de urbanização da Várzea do Gravataí. Diário de Notícias,Porto Alegre, 11 dez. 1937.

\section{Fontes}

- FARIA, Luiz Arthur Ubatuba de. Projecto de um plano de urbanização para um bairro industrial e operário na Várzea do Gravatahy. Porto Alegre: Acervo Benno Mentz, Acervo DELPHUS, PUCRS.

- Atas da Empresa Frederico Mentz \& Cia. de 1928 a 1943. Acervo Benno Mentz, Acervo DELPHUS, PUCRS. 